\title{
OfICINA dE ENSINO, FORMAÇÃO E ESTÁGIO NO FAZER DO ESTUDANTE DE HISTÓRIA ${ }^{1}$
}

\author{
Carlos Augusto Lima Ferreira* \\ calfferreira@gmail.com
}

\begin{abstract}
Resumo: Este texto é um relato do estágio dos estudantes do curso de História da Universidade Católica do Salvador, realizado em três escolas públicas de Salvador e no Arquivo Público da Bahia. O artigo analisa a relação entre a formação desse futuro profissional e o estágio curricular, a partir de discussões teóricas que incorporam as oficinas de ensino. Para os estagiários, a prática nas escolas e no Arquivo Público trouxe a possibilidade de problematizar questões referentes à sua formação e a outros campos de atuação do professor, percebendo a importância do estágio como uma das formas de solidificar o aprendizado.
\end{abstract}

Palavras-Chave: Ensino, História, Estágio.

INTRODUÇÃO

A publicação da nova Lei de Diretrizes e Bases (LDB), em 1996, os Parâmetros Curriculares Nacionais (PCN), em 1998, e as Diretrizes Curriculares de História (Pareceres CNE/CES 492/2001 e 1.363/2001) mostram que as preocupações com o ensino, em geral, e o de História, em particular, em todos os seus níveis, são uma realidade. Simultaneamente aos debates que originaram a referida lei, os parâmetros e as diretrizes, a comunidade acadêmica do curso de História da Universidade Católica de Salvador (UCSal) desencadeou uma ampla discussão, com o objetivo de propor um novo currículo que atendesse a esse cenário. Este processo iniciou-se, a partir do ano 2000, no âmbito dos debates sobre os novos currículos de graduação da UCSal, incentivados pela Pró-Reitoria para Assuntos Acadêmicos dessa instituição.

* Doutorado em Educação pela Universidad Autonoma de Barcelona/Espanha. Professor do Curso de História da UCSal e Professor Colaborador do Mestrado em História Regional e Local da Universidade do Estado da Bahia . 
No caso específico do curso de História, a proposta de reforma curricular sugeriu, enfaticamente,

[...] um curso que evite a dicotomia entre licenciatura e bacharelado, na perspectiva de contemplar conteúdos histórico-historiográficos, metodológicos, pedagógicos e de formação geral; teoria e prática integradas através de estágios realizados ao longo dos estudos, voltados para o desenvolvimento das habilidades cognitivas do graduando. [...] Buscando o estímulo ao desenvolvimento do pensamento reflexivo, crítico e criativo [...] (UCSal, 2004, p.15).

É nesta perspectiva que a proposta buscou ultrapassar a organização curricular baseada em disciplinas estanques e fechadas, desenvolvendo um projeto que comprometesse docentes e discentes com um saber/fazer pedagógico englobando: a compreensão da complexidade da realidade social e dos determinantes históricos da docência; o domínio dos referenciais teóricos e pedagógicos para uma nova prática pedagógica necessária para que o ensino de História seja renovado continuamente.

Neste sentido, busco neste artigo analisar a relação entre a formação do estudante de História da UCSal e a experiência de estágio desenvolvida em três escolas públicas ${ }^{2}$ do ensino fundamental da cidade do Salvador e no Arquivo Público do Estado da Bahia durante o ano de 2007. Para tanto, discuto os temas formação, oficinas de ensino e estágio curricular em seus aspectos teórico-práticos. Não se pretendeu, entretanto, descrever as atividades realizadas, mas mostrar o reflexo destas na formação dos estudantes envolvidos nas disciplinas.

O artigo procura também contribuir com as reflexões produzidas na área, notadamente para professores de ensino básico, acadêmicos dos cursos de História e profissionais das secretarias de educação.

\section{A OFICINA E O ESTÁGIO NO CONTEXTO DA FORMAÇÃO}

A sociedade passa, principalmente nos últimos anos, por muitas transformações que vêm provocando reflexões importantes; e a formação de professores não pode ficar alheia a elas. Nessa direção, é fundamental que o repensar das atividades educativas passe por novas formas de fazer e construir. A simples transmissão de conteúdos centrada nas "verdades" do professor já não atende às necessidades dos estudantes e, conseqüentemente, de uma formação que se pretenda transformadora e libertadora. (FERREIRA, 2006, p.5) 
A formação proposta no currículo de História da UCSal visa buscar a superação da dicotomia entre a Licenciatura e o Bacharelado. A primeira, compreendida como o lugar de formação daquele que será apenas o transmissor do conhecimento - o professor -, ou seja, o ensino de História enquanto simples repasse de informações. O segundo, visto como espaço onde se produz a pesquisa, o conhecimento. Entendemos que o conhecimento histórico é uma construção dos vários sujeitos. Há que se buscar, nesse sentido, a formação integrada do pesquisador e professor, até porque o professor não pode ser considerado um mero reprodutor do conhecimento, mas alguém que o produz.

Dessa forma, estaremos formando sujeitos habilitados para o ensino, a pesquisa e a reflexão crítica acerca da História e de seus processos, capazes de intervir na sociedade.

Sendo assim, é essencial superar a visão de que a pesquisa não deve ou não pode estar afeita à formação do professor. Até porque a pesquisa e a sua relação com o ensino e a educação são inerentes à docência, estando necessariamente presentes no exercício da profissão em qualquer nível ou modalidade de ensino.

A esse respeito, Luis Fernando Cerri demarcou com precisão os desafios postos na formação com ênfase na reflexão e nas construções de estratégias teórico-metodológicas de estudo definidas pela indissociação entre ensino e pesquisa, elegendo a figura do produtor do conhecimento como aquela que define o professor de História na atualidade.

História, no caso, não é pensada como um conteúdo a ensinar a partir de uma metodologia eficiente, mas uma postura intelectual, teórica e metodológica, oriunda da formação do historiador, e que precisa estar presente, não como pressuposto, mas como postura integrada na formação do professor de História. Na verdade, poderíamos mesmo afirmar que não se trata de formar um historiador-professor ou um professor-pesquisador, trata-se de formar especificamente um professor de história, na medida em que a plena realização do sentido do termo professor pressupõe o domínio do conhecimento, da teoria, do método, bem como a capacidade de criação, para além de um ensino de repetição do conhecimento criado por outros. (CERRI, 2006, p. 224-225)

A formação é um elemento gerador de cultura, de reflexão crítica e de novas possibilidades e não apenas e tão somente transmissora de conte- 
údos. Hoje, a formação necessita estar atenta às mudanças do currículo e do saber escolar e às novas organizações espaciais. Uma formação que entenda a importância não só da aquisição de estratégias cognitivas, mas também do papel do estudante como responsável por sua própria aprendizagem.

Dessa maneira, durante a formação inicial, tem-se a possibilidade de desenvolver no processo pedagógico o gosto pela pesquisa e pela produção do conhecimento e de materiais didático-pedagógicos, de forma autônoma e criativa, que possibilite aos futuros professores ensinar História dando sentido e significado aos temas a serem trabalhados nos espaços educativos.

Constitui-se condição sine qua non que o futuro professor de História experiencie, como aluno, em seu processo de formação, as atitudes, modelos didáticos e metodológicos, capacidades e modo de organização que venham a ser concretizados nas suas práticas pedagógicas. Por estes aspectos, o curso de História necessita ser um espaço de construção coletiva de conhecimento sobre o ensino e a aprendizagem.

A oficina de ensino representa no espaço da sala de aula um momento de interação e envolvimento entre os sujeitos. Recorremos à afirmação de Filomena Maria Moita e Fernando Cézar Andrade, para quem:

[...] a oficina pedagógica constitui-se num importante dispositivo pedagógico para a dinamização do processo de ensino-aprendizagem, particularmente por sua praticidade, sua flexibilidade diante das possibilidades de cada escola e, mais que tudo, por estimular a participação e a criatividade de todos os seus integrantes. Conseqüentemente, as oficinas pedagógicas são situações de ensino e aprendizagem por natureza abertas e dinâmicas, o que se revela essencial no caso da escola pública - instituição que acolhe indivíduos oriundos dos meios populares, cuja cultura precisa ser valorizada para que se entabulem as necessárias articulações entre os saberes populares e os saberes científicos ensinados na escola. (MOITA; ANDRADE, 2006, p.11)

Nas oficinas, o professor encontra espaço para a pesquisa e a reflexão onde os alunos possam: - Reconhecer a leitura dos documentos fontes como elementos que proporcionam informação para a investigação; - Adquirir experiência na análise e interpretação dos documentos para, a partir deles, poderem desenvolver a escrita textual; - Aprender a utilizar a capacidade de inferir para formular perguntas e problemas sobre o tema a ser trabalhado.

Estes aspectos são trabalhados nos conteúdos e temas escolhidos, visando possibilitar ao aluno que ele saiba apreender e lidar corretamente 
com a informação na perspectiva da preparação do argumento e do contraargumento. A oficina consolida a formação pela pesquisa, fornecendo ao professor e aos estudantes a oportunidade para desenvolver métodos, instrumentos de análise e a possibilidade de reflexão e tomada de consciência sobre o que está acontecendo em sala de aula.

Cabe, assim, ao professor expor em que consiste o trabalho com oficinas de ensino, distribuindo as tarefas a serem realizadas, selecionando fontes, estimulando o desenvolvimento da pesquisa, incentivando a apresentação, a defesa dos argumentos e a conclusão. Todavia, trabalhar com oficina não se trata de dar respostas prontas e definitivas, mas sim mostrar caminhos de como se aprender a trabalhar com História, problematizando-a em sala de aula.

A formação do estudante de História, além dos aspectos pedagógicos desenvolvidos em aula, onde se insere as oficinas de ensino, também envolve a dimensão prática realizada através do estágio. No geral, a discussão sobre o estágio restringe-se a uma visão meramente pragmática da academia e da instituição onde esta atividade se realiza sobre a inserção do formando no mercado de trabalho.

Entretanto, verificar o olhar crítico do formando com experiências em estágios curriculares sobre o mercado de trabalho e seu processo de formação pode lançar luzes sobre outros mecanismos que venham melhorar a qualificação profissional dos nossos universitários. Ao ingressar no mercado de trabalho, como estagiário, o estudante deve ser estimulado a ter uma posição crítica sobre as duas instituições envolvidas nesse processo: a universidade e a organização conveniada.

$\mathrm{Na}$ formação do professor se faz necessário uma nova concepção de estágio, visto que estamos em um mundo de transformações rápidas. O Brasil experimenta momentos de exigências para enquadrar-se em um modelo "globalizado" mesmo que a nossa sociedade ainda não tenha superado problemas básicos como fome, desigualdade social, analfabetismo, entre muitos outros agravantes de uma vida que urge ser transformada.

De acordo com Selma Garrido Pimenta e Maria Socorro Lucena Lima:

$\mathrm{Na}$ sociedade contemporânea, as rápidas transformações no mundo do trabalho, o avanço tecnológico configurando a sociedade virtual e os meios de informação e comunicação incidem com bastante força na escola, aumentando os desafios para torná-la uma conquista democrática efetiva. [...] Transformar as escolas e suas práticas e culturas tradicionais e 
burocráticas - que, através da retenção e da evasão, acentuam a exclusão social - em escolas que eduquem crianças e jovens, propiciando-lhes um desenvolvimento cultural, cientifico e tecnológico e assegurando-lhes condições para fazerem frente às exigências do mundo contemporâneo [...]. (PIMENTA; LIMA, 2004, p.89)

Sabemos que o mundo do trabalho requer, cada vez mais, um profissional que saiba transitar, crítica e criativamente, por sua área de conhecimento específico e, ao mesmo tempo, que seja capaz de dialogar com os profissionais das demais áreas.

Esse exercício de estar em constante diálogo com as demais áreas do conhecimento é um desafio enfrentado pelo profissional que irá para o ensino fundamental e médio. Sua ação pedagógica será mais eficiente na medida em que suas práticas tenham como base as vivências experienciadas em sua formação acadêmica.

\section{A EXPERIÊNCIA VIVIDA: FAZENDO E REFAZENDO}

A questão do estágio na UCSal e as relações escolas/instituições têm se constituído ultimamente em umas das preocupações centrais da sua política acadêmica. Isto porque o estágio curricular compõe uma etapa particularmente importante da formação inicial dos profissionais por ela formados, e, neste caso específico, os futuros profissionais de História. Nele, o estagiário trabalha em situação de observação e regência, sob orientação do regente de estágio ${ }^{3}$, sendo também acompanhado por professores orientadores das disciplinas de Metodologia e Prática do Ensino de História (MPEH) I, II, III e IV do Curso de História.

Durante o estágio nas escolas de ensino fundamental, no ano de 2007, foram realizadas 20 oficinas de ensino ${ }^{4}$, espaço de aprender a construir uma gama variada de atividades ${ }^{5}$, que contribuíram para a reflexão e planejamento de atividades didáticas para o ensino com base no conhecimento adquirido nas oficinas.

As novas linguagens estão presentes de forma intensa no nosso cotidiano, notadamente no universo das crianças e jovens via televisão, cinema, fotografia, histórias em quadrinhos, charges, músicas, entre outras. Entender, interpretar e compreender suas contribuições a partir das oficinas de ensino favorece o processo de aprendizagem, constituindo-se em um espaço para os educandos do ensino básico se perceber como sujeitos do processo histórico. Sobre isso, diz um estagiário: 
As linguagens alternativas vêm surgindo [...] como elementos fundamentais no processo de ensino-aprendizagem, e a música é uma dessas linguagens. O papel dessa oficina de história é despertar o senso crítico do aluno [...] $\mathrm{O}$ aluno deve se sentir sujeito histórico, a história não deve ser entendida como estudo do passado, factual, linear, distanciada deste aluno. Os sons estão impregnados no nosso cotidiano de tal forma que, na maioria das vezes, não tomamos consciência deles. Eles nos acompanham diariamente, como autêntica trilha sonora de nossas vidas, manifestando-se sem distinção nas experiências individuais ou coletivas. Nossa tarefa é fazer com que o aluno, perceba a importância da música e sua relação com a história. (Estagiário A. Grifos do autor)

Estar em contato com novas possibilidades pedagógicas no seu processo de estágio foi para os estudantes uma motivação, pois reconheceram nesta metodologia - a oficina de ensino - uma forma mais dinâmica e um espaço para a produção pessoal e coletiva sobre o que se estava discutindo.

No estágio do Arquivo Público, buscamos possibilitar aos estudantes do curso uma modalidade de estágio que não estivesse vinculada diretamente às salas de aulas, como é comum, mas uma atividade que possibilitasse a conexão ensino-pesquisa. Assim sendo, os estagiários, em número de oito, foram distribuídos nas diversas áreas de pesquisa que compõem o universo do Arquivo Público do Estado da Bahia, a saber: Colônia e Império ${ }^{6}$, República $^{7}$, Judiciário ${ }^{8}$, Intermediário ${ }^{9}$, Restauração ${ }^{10}$, Biblioteca ${ }^{11}$, Informática ${ }^{12} \mathrm{e}$ Microfilmagem $^{13}$.

Neste sentido, o estágio no Arquivo Público se constituiu em um rico momento para a superação das atividades do estágio supervisionado ${ }^{14}$ comumentes realizadas nos cursos de Licenciatura em História. Esta experiência oportunizou aos estudantes participantes a imersão nas fontes historiográficas, que constituem um dos elementos para a elaboração de produções acadêmicas e materiais didático-pedagógicos a serem aplicados nas oficinas. Assim, para os estagiários:

O contato com as fontes auxiliares no processo de entendimento do estudante, sobre como o conhecimento histórico é construído metodologicamente, de forma que o estudante passa a entender de uma forma palpável como materialmente uma sociedade registra a sua história e a dos seus sujeitos, permitindo ao estudante se perceber, também, enquanto agente histórico. (Estagiário B). 
O contato com os documentos do Arquivo ultramarino e com seus verbetes desperta no graduando em História a certeza de que o contato com as fontes primárias é de suma importância para a formação do estudante... (Estagiário C).

A vivência no Arquivo possibilitou o embasamento prático que, aliado ao teórico, os capacitou - ainda que em um tempo curto - para lidar com as questões pertinentes a documentação histórica. Esta melhor qualificação por certo irá contribuir para atender às necessidades específicas das atividades que deverão desempenhar quando do seu ingresso no mercado de trabalho, quer seja na escola, quer seja em instituições de pesquisa. A propósito, convém lembrar Maria Isabel Cunha, pois para ela:

O desvendamento da prática é que, provavelmente, possa dar mais luzes à trajetória rumo à transformação, uma vez que não há mudança que não ocorra a partir do concreto, da realidade. A constatação de que a educação de professores tem sido mais efetiva pelas influências da prática cotidiana [no estágio] pode influir no repensar dos cursos de formação de professores. (CUNHA, 1992, p.171)

O período de realização do estágio é o momento singular da formação acadêmica, onde o estudante tem a oportunidade de unir a carga de informações teóricas com a prática, possibilitando a produção do conhecimento, superando o papel de passividade, tão comum no processo educativo. Ampliar os horizontes do processo de ensino-aprendizagem para além dos espaços das salas de aula, do quadro-negro e do giz, numa perspectiva crítico-reflexiva são premissas para uma educação que se pretende transformadora.

A oficina [no estágio] sobre a Feira de São Joaquim abriu possibilidades dos alunos fazerem uma reflexão individual e coletiva sobre a formação da comunidade, a extrapolação do espaço-tempo da escola, com a inserção de outras formas de conhecimento na prática escolar e isso nos indica outras formas de pensar a educação. (Estagiário D)

Donald Schön, idealizador do conceito de Professor Prático-Reflexivo, defende uma formação de professores que busque a superação do modelo reprodutivista por outro que capacite o docente a refletir criticamente sobre suas ações. Para ele: 
[...] a formação do professor não se dá em momentos distintos - primeiro a formação teórica e depois a experiência prática -, mas no diálogo da prática com a teoria. Ao refletir sobre a prática o professor desenvolve uma atividade investigativa que irá caracterizá-lo como produtor de conhecimentos práticos sobre o ensino, e não mais como um especialista técnico, que apenas reproduz estes conhecimentos. (SCHÖN, 1991, p.75)

Sobre esses aspectos, estudantes participantes do estágio assim se expressaram:

$\mathrm{Na}$ formação do professor, a sala de aula não pode ser o único local de exercício da profissão [...] No estágio no Arquivo Público estamos tendo contato com documentos como aqueles da revolta dos Malês, jornais de importantes períodos históricos [...] reconheço ser satisfatória a aprendizagem e as experiências lá desenvolvidas. Sendo muito útil para a sala de aula. Ajuda a superar o Livro Didático e buscar novos horizontes, como por exemplo, a produção de pesquisa [...]. (Estagiário E)

É indispensável para o 'fazer história' abrir espaços como esse para a participação dos educadores e educandos, num processo de aproximação com as fontes historiográficas, permitindo a ambos sentirem-se construtores desse processo histórico e não, apenas, meros reprodutores de livros didáticos. (Estagiário F)

O estágio supervisionado, realizado em $\mathrm{MPEH}$, é a última etapa de uma caminhada que se iniciou com as disciplinas de Políticas Públicas da Educação ${ }^{15}$, Psicologia da Educação ${ }^{16}$ e Didática do Ensino de História ${ }^{17}$. A experiência destes estágios contribuiu para a formação dos estudantes, dando-lhes a oportunidade de ter contato com os documentos históricos e a produção das oficinas, favorecendo o processo de interação entre a teoria e a prática pedagógica.

Esta oficina foi realizada a partir da introdução de novas fontes de pesquisa - a fotografia - pouco ou quase nunca utilizada como recurso didático em sala por professores e alunos. Trabalhar com fotografia possibilitou identificar em outros períodos históricos, elementos que compõem a cultura local conectando a História com a realidade. Além de levar os alunos a desenvolverem a capacidade de compreensão, interpretação e escrita. (Estagiário G) 
No processo da formação do estudante, necessário se faz considerar as questões ligadas ao trabalho docente. A prática do Ensino de História deve estabelecer nexos com a forma como a nossa sociedade organiza o trabalho em geral, posto que o trabalho pedagógico é produto de tais relações. Portanto, todo o trato com a disciplina deve ter a preocupação em estabelecer uma articulação entre teoria e prática, conteúdo e forma, ensino e pesquisa. Sobre esse aspecto, Selma Garrido Pimenta e Maria Socorro Lucena Lima apontam que:

A clareza sobre a função do professor, como ator e autor social, tanto na escola como na sociedade, está no horizonte das nossas práticas de formação docente, incluindo o estágio. É necessário, pois, que as atividades desenvolvidas no decorrer do curso de formação considerem o estágio como um espaço privilegiado de questionamento e investigação. (PIMENTA; LIMA, 2004, p.112)

O processo de ensino deve ser entendido como uma prática social do dia-a-dia da instituição educativa, neste caso, da sala de aula - locus dos professores. O ensino é um processo de trabalho, é um processo em movimento. $\mathrm{O}$ ensino não existe em si mesmo, mas na relação com a aprendizagem. Não existe ensino sem aprendizagem. A Prática de Ensino na formação do professor de História deve ser entendida como a articulação entre o domínio dos conhecimentos teóricos de uma área específica e um projeto político-pedagógico particular. As aulas, o relacionamento entre professores e estudantes, a bibliografia usada, o sistema de avaliação, as técnicas e dinâmicas de grupo, os materiais usados, revelam a compreensão e interpretação da relação sujeito-sociedade-natureza historicamente determinada. Essa relação constitui-se na Prática do Ensino, que deve a todo o momento, ser repensada para oxigenar a ação docente.

Deste modo, segundo Selma Garrido Pimenta e Maria Socorro Lucena Lima:

[...] o locus do estágio se estende para além do espaço escolar e da sala de aula, configurando uma possibilidade de leitura de mundo, conforme Paulo Freire. Nessa perspectiva, o estágio tem o sentido de contemplação, trazendo elementos de compreensão da totalidade social que respinga na atividade docente e no cotidiano da sala de aula. Nesse caso, além do desempenho na sala de aula, o futuro profissional da educação vivencia a construção de uma visão mais ampla de atuação na escola, na organiza- 
ção do ensino, na comunidade e na sociedade. (PIMENTA; LIMA, 2004, p.164, Grifos dos autores)

O que essas autoras analisam foi vivenciado na experiência prática deste estudante-estagiário, cujo depoimento ilustra o seu sentimento em relação ao estágio realizado:

O estágio é uma atividade que põe o formando em contato com o universo profissional [...] É indiscutível a necessidade que o professor de História tem de pesquisar e de colocar seus estudantes em contato com o universo da pesquisa. Assim, entendemos que a iniciativa da disciplina é fruto de uma visão mais ampla do papel do educador na sociedade do conhecimento e da sala de aula como algo mais amplo e mais dinâmico que o espaço físico das escolas [...]. (Estagiário H)

Para os estagiários, a prática nas escolas e no Arquivo Público trouxe a possibilidade de problematizar questões referentes à sua formação e a outros campos de atuação do professor/pesquisador, percebendo a importância do estágio como uma forma de complementar o aprendizado. Este aprendizado os estimulou a analisar, interpretar e reinterpretar criticamente as fontes de pesquisa acerca dos aspectos político-econômicos e sócio-históricos subjacentes à nossa História. Anna Bianchi assinala que:

O estágio, quando visto como uma atividade de [sic] que pode trazer imensos benefícios para a aprendizagem, para a melhoria do ensino e para o estagiário, no que diz respeito à sua formação, certamente trará resultados positivos. Estes tornam-se ainda mais importantes quando se tem consciência de que as maiores beneficiadas serão a sociedade e, em especial, a comunidade a que se destinam os profissionais egressos da universidade. (BIANCHI, 2001, p.16)

\section{CONSIDERAÇÕES FINAIS}

No universo da formação acadêmica não se pode partir da premissa de que qualquer ação ou atividade seja mais importante que outra, particularmente na dicotomia entre Licenciatura e Bacharelado. Por conseguinte, assim como o processo de ensino, a pesquisa abriu novos caminhos para estes estudantes, que, por certo, solidificarão o saber de cada um. 
Vivenciar a aprendizagem a partir das oficinas e, ao mesmo tempo, participar do processo de pesquisa, descrevendo e discutindo as práticas pedagógicas e a reação dos seus alunos, deram início a uma outra possibilidade/modalidade de estágio supervisionado.

O estágio, tanto nas escolas como na instituição Arquivo Público, estimulou os estudantes/estagiários a analisar, interpretar e reinterpretar criticamente as fontes de pesquisa acerca dos aspectos político-econômicos e sócio-históricos subjacentes à nossa História. As oficinas contribuíram para a ampliação dos conhecimentos pedagógicos a serem aplicados em sala de aula, bem como para o entendimento acerca das diversas questões do mundo, estimulando a capacidade de intervir adequadamente na realidade como sujeitos protagonistas.

Nesse sentido, o papel da universidade é fundamental na formação oferecida aos futuros professores que atuarão no ensino básico.

TEACHING WORKSHOPS, FORMATION AND TRAINING FOR HISTORY STUDENTS

Abstract: This essay deals with training experience of the History students from Catholic University of Salvador, carried out in three public schools in the city of Salvador and in the Public Archive of Bahia. This article analyzes the relationship between the formation of future professional and the curricular period of training from theoric arguments that incorporates teaching workshops. For these students, the practical activities in schools and in Public Archive brought the possibility of a critical view about their formation and other work fields for the teacher, perceiving the importance of the training as one form of complementing the learning.

KeY-WoRds: Teaching. History. Training.

NOTAS

1 Este texto foi apresentado no VI Encontro Nacional Perspectivas do Ensino de História, realizado na Universidade Federal do Rio Grande do Norte em 2007 e revisto para esta revista.

2 Colégio Estadual Úrsula Catarino, Colégio Estadual Leopoldo Reis e Colégio Municipal Cidade de Jequié.

3 Professor de História da escola conveniada e coordenador de estágio desta instituição.

4 Distribuídas em temas e sub-temas: O Filme em sala (Cleópatra; 1492: A 
Conquista do Paraíso; Lutero; Ó Paí, Ó); Educação Patrimonial (O 2 de Julho; A Feira de São Joaquim; Feira dos Caxixis; Culinária baiana); Música (Jovem Guarda; Apesar de você; Pra não dizer que não falei das flores; Cálice; Revolta Olodum; O Haiti é aqui; Racismo é burrice); Quadrinhos e Charge; Teatro e História; História Local; A Fotografia e História; Museu e História.

5 Confecção de material didático, pesquisa, leitura de artigos e textos, discussões em grupos, discussões nas aulas, consultas bibliográficas, relatos orais e relatórios escritos das atividades desenvolvidas durante o estágio.

6 Mantém a guarda de toda documentação do período Colonial até o final do Império, tais como as Cartas Régias, os Autos da Devassa da Revolta dos Búzios e dos Malês e a carta de doação da Ilha de Itaparica, entre outros documentos de inestimável valor histórico.

7 Seu acervo contém jornais, livros de domínio de marcas, coletânea de discursos de parlamentares, entre outros.

8 Esse setor armazena documentos de partilha de bens, divórcios, compra e venda de imóveis e terras, etc.

9 Responsável pelo guarda de documentos ligados à Secretaria de Segurança Públi$\mathrm{ca}$, e que ainda não podem ser repassados para o arquivo permanente, devido à sua possível requisição, por alguns dos órgãos ligados à mesma (Instituto Médico Legal, Tribunal de Justiça, Delegacias, etc.).

10 Possui equipamentos para o processo de limpeza dos documentos, através da higienização, lavagem com água ionizada e desinfestação de parasitas. Realiza também a secagem do material em restauro, a restauração manual e mecânica dos papéis, enxerto das fibras e encadernação.

11 Responsável pela guarda dos livros do Arquivo e onde se existe um catálogo informatizado de todo o acervo material.

12 Responsável pelos assuntos de informática e pela digitalização do acervo, bem como o abastecimento dos bancos de dados de consulta do Arquivo Público.

13 Responsável pela recepção, montagem e preparação dos documentos para microfilmagem e revelação, assim como a conservação e catalogação do microfilme.

14 Ainda que este seja um termo carregado de influência tecnicista, reforçando o estágio apenas como momento de prática, buscou-se ressignificar a terminologia ao desenvolver esse trabalho que foi além dos aspectos técnicos.

15 Nesta disciplina é desenvolvida a análise da educação brasileira, com ênfase nos aspectos legais, estruturais e técnico-administrativos.

16 Abordagem dos aspectos teóricos e fundamentos das principais correntes psicológicas, identificando-as na prática educacional e analisando as variáveis que interferem no processo de desenvolvimento e da aprendizagem no âmbito da escola. 
17 Organizada de forma que os estudantes pudessem planejar, escolher e construir material didático-pedagógico, bem como pesquisar e preparar projetos de intervenção para as aulas de História na comunidade escolar.

\section{REFERÊNCIAS}

BIANCHI, Anna Cecília de Moraes et al. Manual de orientação do estágio supervisionado. São Paulo: Pioneira, 2001.

CERRI, Luis Fernando. Oficinas de ensino de história: pontes de didática da história na transição do currículo de formação de professores. Educar, Curitiba, n. 27, p. 221-238, 2006. Editora UFPR.

CUNHA, Maria Isabel da. O Bom Professor e Sua Prática. Campinas/SP: Papirus, 1992.

Departamento de História da UCSal. Projeto de reforma curricular do Curso de História. Salvador, 2004.

FERREIRA, Carlos Augusto Lima. La práctica y sus reflejos en la formación del estudiante de Historia: la experiencia en el Archivo Público de la Fundación Pedro Calmon. Havana, Cuba, 2006. In: VII Taller Internacional de Problemas Teóricos y Prácticos de la Historia Regional y Local, 2006, Havana.

MOITA, Filomena Maria; G. S. Cordeiro; ANDRADE, Fernando Cézar B. O saber de mão em mão: a oficina pedagógica como dispositivo para a formação docente e a construção do conhecimento na escola pública. In: Anais Educação, Cultura e Conhecimento na contemporaneidade: desafios e compromissos. Caxambu, MG: ANPEd, 2006.

PIMENTA, Selma Garrido e LIMA, Maria Socorro Lucena. Estágio e docência. São Paulo: Cortez, 2004.

SCHÖN, Donald A. Formar Professores como profissionais reflexivos. In: NÓVOA, António (Org.). Os professores e sua formação. Lisboa: Dom Quixote, 1997. 